\title{
Capturing the Benefits of Digitalization and Service Innovation: \\ A Business Network Perspective
}

\begin{abstract}
A core challenge for broad adoption of the Internet of Things (IoT) is to ensure that its benefits are captured by a wide range of stakeholders. Taking a business network perspective, this study: i) examines the benefit potential of widespread IoT-based digitalization and service innovation; ii) identifies key barriers to capturing these benefits; iii) develops recommendations to overcome these barriers. A three-stage qualitative methodology (based on interviews, a focus group and Delphi-based inquiry) examines the case of an emergent IoT-based digital business network in the UK road transport industry. The research reveals the critical importance of managers involved in digitalization initiatives balancing their interests with those of the wider business network, if the potential benefits are to be captured. It provides fresh insights into: i) IoT-based digitalization as a business network phenomenon; ii) the interplay between digitalization and innovation in the sphere of service business models; iii) digitalization's disruptive impact on 'traditional' industries and the implications for future management research.
\end{abstract}

Keywords: Digitalization, Internet of Things, IoT, business network, servitization. 


\section{INTRODUCTION}

The widespread digitalization brought about by the development and spread of the Internet of Things (IoT) is generating substantial opportunities for innovation and value creation (e.g. McKinsey Global Institute, 2015). Integrating a range of different capabilities (sensing, networking and processing), digitalization implies extensive reconfiguration of everyday products in terms of both their scope and their function (Whitmore, Agarwal, \& Da $\mathrm{Xu}, 2015)$ - a reconfiguration that creates opportunities not only for unbound distributed innovation across all kinds of firms and disciplines (Yoo, Henfridsson, \& Lyytinen, 2010a) but also for the development of novel value propositions (Lyytinen, Yoo, \& Boland Jr, 2016) As the diffusion of the IoT accelerates, the ability to identify ways both of stimulating digitalization's innovation potential and of developing an organizational environment appropriate to harnessing and exploiting the business opportunities has become an important management challenge.

One key area where widespread digitalization has had an impact is product-service transformation - the process whereby manufacturing firms progressively shift from productto service-focused business models and which is commonly referred to as 'servitization' (Baines \& Lightfoot, 2013). It is argued that this transformation delivers substantial economic and strategic benefits both for manufacturers (seeking to extend their customer relationships) and for customers (seeking to focus on their core competencies) (Raddats, Baines, Burton, Story, \& Zolkiewski, 2016). Where servitization is concerned, widespread digitalization is a critical enabler as it allows manufacturers to monitor their product-in-use and ensure that the contracted service value is provided (Grubic, 2014). However, while digitalization and servitization together provide manufacturers and their customers with substantial opportunities, a lot of these are not fully captured (Kastalli \& Van Looy, 2013), leading to 
reports of disillusionment or even abandonment of strategic initiatives in this area (Benedettini, Neely, \& Swink, 2015; Valtakoski, in press).

A critical issue for capturing the benefits of digitalization and servitization is the interorganizational implications of the two phenomena. Digitalization leads firms to rely on product performance/use data created by other parties, which intensifies interdependence between firms (Tilson, Lyytinen, \& Sørensen, 2010). Similarly, servitization leads manufacturers to integrate their objectives and processes with their customer base in order to create the pain/gain-share that underlies their service-value proposition (Baines \& Lightfoot, 2013). Hence, to examine the challenges of capturing the benefits of digitalization and servitization, it is critically important to expand the scope of research beyond a focus on individual firms.

The present study adopts a business network perspective (Johanson \& Vahlne, 2011) to frame and analyse the benefit potential of digitalization and servitization and the barriers to capturing these benefits. A business network perspective considers individual firms within the context of their interdependence and examines the complex interplay that determines firms' behaviour, inter-firm relationships and wider network developments (Snehota \& Hakansson, 1995). The study argues that adopting a business network perspective provides a revealing lens that helps to better understand the implications of digitalization and servitization and examine the multi-level challenges involved in capturing their benefits.

Specifically, this study sets out to address the following two research questions (RQs):

RQ1: What firm-level, relationship-level and network-level barriers limit opportunities for capturing the benefits of digitalization and servitization?

$R Q 2:$ What recommendations can be proposed to overcome these barriers?

To answer these questions, the paper examines an emergent business network within the UK road transport industry whose members are increasingly adopting digitalized products 
and new service-based business models. A three-stage qualitative research methodology is used to investigate the barriers to benefit capture and elicit recommendations on how to address them. The analysis identifies how a range of barriers - an inhibiting culture, a lack of exchange standards, uncertainty over the distribution of both value and risk, and limited availability of resources - all impede the ability to capture the benefits of digitalization and servitization for the individual firms and the wider network. The strategies identified to tackle these barriers include a focus on the provision of training, management innovation and establishment of leadership roles.

The study and its findings make three major contributions to the management and servitization literature: It explores the interaction of digitalization and servitization and the interdependent challenges presented by these two phenomena; by doing so, the paper provides a direct response to recent calls to explore the cross-fertilization between digitalization and servitization (Lusch \& Nambisan, 2015). It conceptualizes the digitalization phenomenon as a driver for the development of emergent business networks; by doing so, the paper creates a reference point for the anticipation, by Lyytinen et al. (2016), of new interorganizational governance structures brought about through digitalization. It derives community-based recommendations for capturing the benefit potential of digitalization and servitization in emergent business networks in general and the road transport industry in particular.

Following this introduction, a focused review of relevant literature on business networks, digitalization and servitization identifies opportunities for integrating these different research domains. The UK road transport industry is then described, together with the three-step research methodology adopted in this study. The paper concludes by discussing its findings and its theoretical and practical implications. 


\section{LITERATURE REVIEW: BUSINESS NETWORKS, DIGITALIZATION, SERVITIZATION}

This section reviews the core contributions of the existing literature on these three domains, in order to identify complementarities and to conceptualize a network perspective on IoT-based digitalization and its implications.

\section{Business networks}

A business network is formally defined as a "set of two or more connected business relationships, in which each exchange relation is between business firms that are conceptualized as collective actors" (Anderson, 1994: 2). 'Connected relationships' imply that firms' exchanges are contingent on exchanges with other firms (Johanson \& Vahlne, 2011). Business network research ${ }^{1}$ examines network developments and the impact of network members' activities, objectives and their network context (Halinen \& Törnroos, 2005). Conceptualizations of business networks focus on the complexity of interactions between firms and are considered an alternative to market-based perspectives for explaining a firm's behaviour (Möller, 2013).

The business value of a network is derived from the interactive and interdependent activities of its members ('value co-creation') (Vargo \& Lusch, 2010). Balancing the individual members' 'firm-interest' and the network's 'collective interest' in capturing business value is of core concern, particularly as this balance is sensitive to technological trajectories and environmental dynamics that can have differential effects on member firms (Munksgaard \& Medlin, 2014).

${ }^{1}$ Business network research, with its focus on interdependencies between firms, differs in objective and scope from social network research, with its primary focus on examining the social structure and dynamics of connected individuals (Oinas-Kukkonen, Lyytinen and Yoo, 2010). 
Business network conceptualizations emphasize the non-hierarchical nature of the underlying inter-firm relationships (Provan, Fish, \& Sydow, 2007), which renders business networks 'weakly manageable' (Möller \& Rajala, 2007). In fact, the mechanisms that govern business networks include: resource ties (members' ability to access each other's resources), activity links (members' operational connections and mutual adaptations) and actor bonds (members' relationships and mutual perceptions) (Snehota \& Hakansson, 1995).

The notion of business networks contrasts with other conceptualizations of loose horizontal inter-firm collaborative structures. Unlike 'boundaryless organizations' (Hirschhorn \& Gilmore, 1992), business network conceptualizations emphasize the complex resource interdependencies that simultaneously affect firm- and network-level activities (Gadde, 2014). 'Business ecosystems' generally form around central (technology-based) platforms (Li, 2009) or firms (Iansiti \& Levien, 2004) instead of decentralized business network relationships (Provan et al., 2007).

The present paper focuses on emergent business networks, a specific scenario that organically develops from repeated interactions between firms (Raab \& Kenis, 2009) and so contrasts with formally designed networks. Although general network attributes are shared (e.g. non-hierarchical, simultaneous competition and collaboration), emergent business networks are distinguished through their ambiguity of boundaries, memberships, roles and relationships (Inkpen \& Tsang, 2005). Emergent networks in particular face the challenges of maintaining collective identities (Raab \& Kenis, 2009), developing network objectives (D'Aunno \& Zuckerman, 1987) and maintaining effective interactions among, and contributions from, an often highly diverse membership (Möller \& Svahn, 2009).

Despite the substantial body of literature relating to the topic, 'business network research' represents a research perspective rather than a theory in its own right (Möller, 2013). Adopting a 'business network perspective' commonly implies that a study seeks to 
analyze and understand a phenomenon across three closely interconnected levels of analysis (Ramos, Roseira, Brito, Henneberg, \& Naudé, 2013; Snehota \& Hakansson, 1995): the firm level, the relationship level and the network level. All three are understood to influence one another through interaction and interdependent coevolution (Welch \& Wilkinson, 2002) and together provide a structure to analyze business phenomena and their underlying theories from an aggregated holistic perspective.

Business network studies particularly draw on resource dependency theory (Pfeffer \& Salancik, 1978) to examine how member interactions are guided by reliance on other members' resources (Möller, 2013) and how resource ownership creates network influence (Elg, 2000). Capability theory, and dynamic capability in particular, is used in business network studies to explore how specific competencies and the ability to adjust these interactively affect network behaviour (Zaefarian, Henneberg, \& Naudé, 2011). From a business network perspective, capabilities are located either in individual firms (e.g. capabilities that firms require for effective network utilization) (Walter, Auer, \& Ritter, 2006) or in the network (e.g. capabilities that need to be present for the network to create value) (Möller \& Svahn, 2003).

Prior investigations have revealed the challenges of investigating business networks. Firms, through close interaction with separate sets of business partners or interaction domains, are part of various overlapping networks (e.g. operational or R\&D networks), highlighting the complexity challenge of identifying and isolating the particular network of interest ('focal network') (Halinen \& Törnroos, 2005). Identifying the network boundary is another challenge. Business networks (particularly emergent networks) extend without formal limits, so it is critical to set a boundary for the investigation "as one can never study the entire [...] network" (Halinen \& Törnroos, 2005: 1287). A third challenge is to establish a network view that represents the shared understanding held by different network actors (Henneberg, 
Naudé, \& Mouzas, 2010). Network views do not exist in a concentrated form but are dispersed in the form of cognitive 'pictures' held by individuals within the business network (Henneberg, Mouzas, \& Naudé, 2006). Establishing a shared network view involves integrating the dispersed (and at times contradictory) cognitive pictures held by those participating in the emergent business network (Ford, Gadde, Hakansson, \& Snehota, 2003; Henneberg et al., 2006).

The research presented in the current paper adopts a business network perspective to explore digitalization and servitization opportunities and to analyze the multi-level barriers that prevent network members from capturing the benefits.

\section{Digitalization and its role in network formation}

The IS literature defines digitalization ${ }^{2}$ as "the practice of taking processes, content or objects that used to be primarily (or entirely) physical or analog and transforming them to be primarily (or entirely) digital" (Fichman, Dos Santos, \& Zheng, 2014: 333). Infusing products with digital technology generates new properties spanning communication, programmability and traceability (Yoo, Lyytinen, Boland, \& Berente, 2010b); it also changes the nature of the product (Yoo, Boland Jr, Lyytinen, \& Majchrzak, 2012), creates new potential functionalities (Fichman et al., 2014) and turns the user into a contributor of data (through product use as opposed to distributed browser-based web 2.0 technologies) (Kreps \& Kimppa, 2015).

The benefit opportunities that digitalization creates for industrial firms and their business partners are diverse. Coreynen et al. (2016) differentiate between opportunities for enhancing a firm's back-end operations (e.g. resource monitoring), for improving its front-end operations (e.g. understanding customers' processes) and for radically changing customer

2 The term 'digitization' is often used as an alternative (Vendrell-Herrero, Bustinza, Parry and Georgantzis, in press). 
processes (e.g. providing additional services to customers). Digitalization enables these opportunities through predictive analytics (Nadj, Jegadeesan, Maedche, Hoffmann, \& Erdmann, 2016), real-time virtualizing (Wang, 2016) or innovation (Yoo et al., 2012). However, realizing these opportunities requires access to performance/use data generated outside a firm's traditional boundaries.

Digitalization has a strong impact on inter-firm relationships. Performance/use data becomes a fluid resource that firms share and recombine to create digital innovation (Tilson et al., 2010; Yoo et al., 2010a). In effect, digitalization extends the 'generativity' notion beyond its original software context (Zittrain, 2006) to a product context, by enabling collaborating or competing firms to integrate and use the product (particularly its performance/use data) in ways that the designer did not intend (Tilson et al., 2010). Digitalization therefore extends a product's benefit potential from its immediate user to a wider range of stakeholders who utilize the product data, integrate their value creation activities and intensify their interdependencies (Lyytinen et al., 2016).

The interdependencies that are caused by digitalization require firms to increasingly integrate the business network into their decision-making (Bharadwaj, El Sawy, Pavlou, \& Venkatraman, 2013). Purposefully 'incomplete' digitalized products serve as distributed innovation platforms (e.g. app development for Apple's iPad) (Tilson et al., 2010) and the product's functionality - and ultimately its value - is determined by the network's innovation capability (Nambisan, 2013; Yoo et al., 2012). Although business networks accelerate digital innovation opportunities, they also introduce additional complexities of Intellectual Property (IP), data ownership and standards (Nambisan, 2013).

As digitalization requires firms to expand their management focus understanding the new interdependencies it creates and identifying ways to manage them in order to capture the benefit potential becomes critical. In this context Venkatraman et al., (2014) have started to 
explore the role of network-based digital capabilities that enable firms to capture the benefit potential of digitalization. They propose that firms need new operational, dynamic and improvisational capabilities in order to manage their network interactions. However, a firm's ability to capture the benefits of digitalization depends not only on the firm's relationship with its wider network but also on the strength of the network and the establishment of mechanisms for sharing these benefits among network members (Riggins \& Wamba, 2015). A multi-level business network perspective can be expected to shed new light on the diverse implications digitalisation creates in a particular business context. The review will next focus on the servitization context as a particular business scenario for digitalization.

\section{Servitization and its role in network formation}

Servitization is one of the important business model innovations that benefit from widespread digitalization. The servitization literature concentrates on manufacturing firms that re-orientate themselves to compete through a portfolio of integrated product-based services rather than just the physical product itself (Baines \& Lightfoot, 2013). One such service is Rolls-Royce's 'power by the hour' where the product (i.e. the jet engine) is used as the platform for providing propulsion services to airlines (Ng, Parry, Smith, Maull, \& Briscoe, 2012); here, the jet engine and its performance remain Rolls-Royce's responsibility. Servitization provides manufacturers with a range of opportunities, including market differentiation, extension/protection of customer relationships and extension of product lifecycles (Neely, 2008).

The theoretical grounding of servitization is provided by Vargo and Lusch's (2008) service-dominant (S-D) logic, which stipulates that all commercial interactions are servicebased and products are distribution mechanisms for the service. Value (in the form of service value) is created through product use, which challenges the traditional goods-dominant logic where the production and distribution of products is seen as the source of value creation 
(Kowalkowski, 2010). S-D logic views the supplier as a collaborative resource integrator who co-creates value with the customer.

In an industrial context, S-D logic has wider network implications that go beyond the immediate service-exchange dyad (Lusch \& Nambisan, 2015): because a firm's customers also act as resource integrators for other firms, a set of service-based network-like interdependencies evolve (Fisk, Patricio, Kowalkowski, Kindström, \& Witell, 2011). Elsewhere (e.g. Lusch \& Nambisan, 2015), the term 'service ecosystem' is used to describe how, through their mutual service-based value creation, loosely coupled resource integrators evolve into interconnected, self-adjusting business networks.

Although servitization research is largely firm-focused (see Baines, Lightfoot, Benedettini, \& Kay, 2009), more recent investigations have started to examine how servitizing firms utilize their networks to source critical capabilities (Kindström \& Kowalkowski, 2014) and innovate their service propositions (Story, Raddats, Burton, Zolkiewski, \& Baines, in press). This expanding research scope argues that servitization extends beyond a firm-level transformation as it involves a firm's wider business relationships, where it can unbalance and disrupt established dependencies and power relationships (Vendrell-Herrero, Bustinza, Parry, \& Georgantzis, 2017). Understanding the interdependencies servitization creates across business-networks becomes critical for developing strategic guidance for firms seeking to capture its benefit potential.

The servitization literature has also started to explore the critical link between servitization and digitalization by highlighting how product use/performance data acts as a key enabler of product-based service innovation and delivery (Barrett, Davidson, Prabhu, \& Vargo, 2015). Coreynen et al. (2016) identify digitalization as a critical dynamic capability which allows servitizing firms to continuously revise their service offering through risk assessment and mitigation. Other digitalization benefits for servitization include minimized 
product downtime, evidence-based risk management, cost-efficient service delivery and extensive R\&D feedback (Grubic, 2014; Kindström \& Kowalkowski, 2014; Opresnik \& Taisch, 2015). The role of digitalization as a critical driver of servitization is increasingly recognised, with studies starting to use the term 'digital servitization' to highlight the tight integration between these two domains (Schroeder \& Kotlarsky, 2015; Vendrell-Herrero et al., 2017).

This literature review has identified how, in conjunction, digitalization and servitization enable new product-based service propositions and act as catalysts for firms' network formation. In the context of emerging networks, it therefore becomes critical to understand the barriers to capturing these digitalization and servitization benefits across the network.

\section{THE RESEARCH}

\section{Background}

In order to identify, firstly, the barriers to capturing the benefits of digitalization and service transformation and, secondly, recommendations for overcoming these barriers, this study examines an emergent business network within the UK road transport industry. This industry involves a diverse set of stakeholders, such as transport operators, original equipment manufacturers (OEMs, e.g. vehicle manufacturers) and telematics providers.

Digitalization in the form of telematics is increasingly being adopted and utilized by the different stakeholders, and vehicle manufacturers increasingly offer product-service contracts that utilize extensive telematics technology (Musson, Bigdeli, \& Baines, 2015). Telematics within road transport involves sensors and connectivity devices that continuously create and transfer data about vehicle location and status, for example covering revolutions per minute, oil pressure, seatbelt use, engine idling and the use of cruise control (Watson, Boudreau, Li, \& Levis, 2010). These detailed insights not only help vehicle operators to identify utilization 
inefficiencies but also assist vehicle manufacturers in evaluating their product performance and refining the understanding of their customers. By 2016, 30\% of UK road transport operators had adopted telematics systems for their fleets (Cole, 2016).

Telematics-based digitalization is an essential enabler of service transformation in an industry where manufacturers have started to offer products such as trucks and tyres through service packages (Baines \& Lightfoot, 2013; Dalsace, Ulaga, \& Renault, 2012). For instance, vehicle manufacturer MAN currently offers UK operators 15,000 trucks as part of a pay-peruse transportation service proposition (including guarantees on availability and total cost of operation). Telematics data allows manufacturers to monitor products-in-use, which is essential to ensuring delivery of their service commitment.

The growing interdependence of road transport firms' value creation activities justifies the adoption of a business network perspective to investigate barriers to the capture of digitalization and servitization benefits and to develop recommendations for overcoming them (Möller \& Halinen, 1999). The network perspective is adopted as an analytical framework (Welch \& Wilkinson, 2002) to identify, describe and understand the complex and interdependent nature of the benefit capture barriers across the network's multiple levels of analysis (firm, relationship, network) (Tikkanen, 1998).

\section{Research methodology}

In order to investigate the benefit capture barriers affecting road transport networks, this study employs a qualitative research method rooted in a 'moderate constructionist' perspective (Van Den Belt, 2003). Qualitative methods are frequently employed as they enable close iterative interaction with network members, in order to overcome the network investigation's complexity challenge (i.e. identifying a focal network by enabling contextsensitive interpretations) and boundary challenge (i.e. investigating the network boundaries by leveraging the members' perceptions ('network horizons')) (Halinen \& Törnroos, 2005). 
Following the 'moderate constructionist' perspective (Järvensivu \& Törnroos, 2010) the study draws data from a single case to identify the "local, community- bounded, interacting forms of truth that are created and validated through dialogue in different communities" (p101). A three-stage qualitative method was adopted to elicit these community insights:

- Stage One: individual interviews and thematic analysis identified the benefit potential of digitalization and servitization, confirmed the applicability of a network perspective and formulated the boundary of the network.

- Stage Two: a focus group was used to identify the barriers to benefit capture and to develop a shared network view on the main barriers.

- Stage Three: a Delphi-based approach developed community-based recommendations for overcoming the benefit capture barriers.

Stage One: individual interviews and thematic analysis. The first stage in the research sought to identify the benefit potential of digitalization and servitization for the road transport industry, confirm the applicability of a network perspective and formulate the boundary of the focal network for the further course of the investigation. To address these objectives, individual interviews were conducted to obtain valid insider perspectives from core network member representatives (Järvensivu \& Törnroos, 2010). Seven senior managers were interviewed, representing a diverse range of closely interdependent road transport firms (vehicle manufacturer, telematics provider, component manufacturer, operators - see Appendix 1). The firms were selected for their operational and strategic dependence on shared telematics systems/data and (in some cases) explicit service contracts.

The interviews lasted between 20 and 40 minutes and followed a semi-structured format with questions focusing on: i) the benefit potential that digitalization and servitization can create for the firms; and ii) the difficulties involved in achieving these benefits. Two of the 
interviews were carried out face-to-face, recorded and then transcribed; the other five were conducted over the phone and not recorded, although extensive notes were taken for later analysis. The analysis focused on producing short vignettes from the interview data (i.e. "focused description[s] of...events that are taken to be representative, typical or emblematic [of] the case", Miles \& Huberman, 1994: 81). These vignettes were analysed by the research team through a joint iterative thematic analysis process (Braun \& Clarke, 2006) focusing on the identification of the firm's potential and obtained benefits, and their interdependencies with other firms.

The detailed findings are presented in section 3.3. In summary, the analysis i) identified the diverse benefit potential of digitalization and servitization, ii) confirmed the applicability of a network perspective by showing how, for all stakeholders, the opportunities for benefit capture are contingent on other firms' activities (Möller \& Halinen, 1999) and iii) created insights on the network boundary; descriptions of benefit potential differentiated between the role of partner firms (vehicle manufacturers, telematics providers, transport operators) and customers (e.g. supermarkets), indicating the participants' 'network horizons' (Halinen \& Törnroos, 2005).

Stage Two: identifying and prioritizing the main barriers. The second research stage sought to identify the barriers that limit the benefit capture opportunities of digitalization and servitization, and to develop a shared network view on their importance. A focus group was identified as a suitable method to extract individual perspectives while also providing a platform for discussion and integration (Sutton \& Arnold, 2013). Specifically, the focus group was used to elicit individuals' 'cognitive pictures' (Henneberg et al., 2006) on the benefit capture barriers they perceived, and to integrate the cognitive pictures in order to establish a shared 'network view' (Matthyssens, Vandenbempt, \& Weyns, 2009). 
The focus group involved 17 senior managers representing eight interdependent memberfirms of the focal network (see Appendix 1). In addition to the vehicle manufacturer, telematics provider and operator represented in Stage One, three additional operators and a fleet management provider were invited to take part, to expand the diversity of perspectives. As before, the firms were selected for their dependence on the shared telematics system and data and (in some cases) service contracts. Assembling these senior managers in a single focus group provided a rare research opportunity, as previous dealings between these members of an emergent business network had been limited to pairwise interactions.

A structured three-step process was followed to elicit the participants' network pictures and establish a shared network view on the benefit capture barriers:

1) Participants identified factors limiting their firm's ability to utilize the potential benefits of digitalization and servitization. Each factor identified was noted on a separate card to create a permanent record of the participant's examples of benefit capture barriers and was explained to the other participants; a total of 68 cards were created and displayed.

2) Participants iteratively consolidated the cards into related examples and grouped these into themes representing the overarching barriers recognized. A total of 10 themes emerged through this participant interaction, representing the group's consolidated and shared view on the overarching barriers to benefit capture.

3) Participants ranked these overarching barriers according to their relative importance, creating a comprehensive network view which pinpointed and prioritized the barriers to benefit capture; they then reflected on the barriers identified and provided background information regarding the themes' implications for their own firms.

The focus group session lasted for four hours and was moderated by a senior academic with facilitation experience; a further four academics assumed supporting roles, taking notes 
on the arguments and exchanges. The session was followed by debriefing of the five academics to consolidate notes and insights obtained. The focus group served as a method to create an inductive understanding ('shared network view') of the benefit capture barriers of digitalization and servitization. The subsequent analysis focused on interpreting the barriers through the lens of a business network perspective. The research team used their field notes to position the barriers in a network context and analyze the implications for the wider business network. The detailed description of the barriers and their network implications is presented in section 3.3.2.

Stage Three: developing recommendations. The third stage sought to develop recommendations for overcoming the benefit capture barriers. A Delphi-based method was identified as a suitable group mechanism for eliciting and consolidating real-world expertise on complex problems and future events ('what could/should be') (Hsu \& Sandford, 2007). Although studies differ widely in their application of the Delphi method (Donohoe \& Needham, 2009), guidelines highlight the importance of developing a panel of subject-matter experts who have a stake in the study's outcome and will therefore campaign for their views to be represented (Hsu \& Sandford, 2007). For the present study, a panel of seven senior experts was drawn from the focal network - seven being an appropriate number to create a meaningful diversity of views (Donohoe \& Needham, 2009). The panel included representatives of the manufacturer, telematics provider and operator firms involved in the emergent network (see Appendix 1).

Via email, the panel members received a summary of the benefit capture barriers previously identified together with a request to provide concrete recommendations on how these barriers could be overcome. The research team synthesized the diverse responses with a focus on integrating the diverse contributions and aptly representing the recommendations provided. The researchers then redistributed the synthesized responses to provide the panel 
members with an opportunity to review and comment on the recommendations, which led to two additional contributions (for clarification purposes). Although originally a third round of interaction had been envisaged, the process was concluded after this second round (following Donohoe \& Needham, 2009) as none of the panel members further challenged the synthesized recommendations. The final recommendations are summarized in section 3.3.3 and set out in detail in Appendix 2.

\section{Research findings}

Stage One findings: benefit capture as a network challenge. The interview stage provided important insights into the benefit capture opportunities that digitalization and servitization create for the network members and into the inter-firm dependencies that underlie these opportunities (see table 1).

For transport operators, digitalization presents opportunities to better manage driver behaviour and optimize fleet performance; however, capturing these benefits depends on both access to and the quality of the telematics data made available by the vehicle manufacturer and the telematics provider.

For the vehicle manufacturer, digitalization makes it possible to obtain important insights on the use of their vehicles and provides a critical basis for managing the risks of providing the vehicle as a service proposition (i.e. servitization). The manufacturer's representative commented:

“[The trucks] are a mobile research and development area, we're getting real $R \& D$ information that's fed back then to production, to engineering, to suppliers, so it leads to reduced [risk and cost]."

(Chief Executive Officer, Vehicle Manufacturer)

However, securing these benefits depends on the operator's decision whether to utilize the default-telematics system and grant the manufacturer access to the data produced. It is 
important to note that, where the truck is provided in the form of a service proposition, ownership of vehicle data remains with the manufacturer.

For the telematics provider, a higher extent of digitalization allows for a continuous refinement of analytical processes, as well as scope to provide operators and manufacturers with benefits they cannot create themselves:

"[Manufacturers] will never succeed in this is because it takes them seven years to build a product, yes, a new product, operators, if they want a change of data or if they want more of this or less of that, they want it now, they're not prepared to wait seven days, seven weeks, seven months, which is what it would take an OEM to bring about a change ....[we] will bring about a change in weeks or months that it would take the OEM years, and that's the difference, the speed of reaction."

(Managing Director, Telematics Provider)

However, the distribution of telematics systems (via manufacturer or operator adoption) as well as the level of access to core vehicle systems data determines the benefits that can be captured.

The interviews revealed a high level of interdependence regarding firms' benefit capture opportunities, which suggested that a business network perspective presents an appropriate frame for investigating the benefit capture barriers relating to digitalization and servitization (Johanson \& Vahlne, 2011). Descriptions of the interdependencies largely focused on interactions between manufacturers, operators and the telematics provider, which provided an indication of the network boundary to be considered during the further course of the investigation (Halinen \& Törnroos, 2005).

Position of Table 1: Benefit capture opportunities 
Stage Two findings: a network view on the benefit capture barriers. The focus group produced a network view on the barriers to benefit capture relating to digitalization and servitization (Henneberg et al., 2006). It identified and prioritized four overarching barriers that are analyzed here along with their firm-level, relationship-level and network-level manifestations (see table 2).

Inhibiting culture was prioritised as the most important barrier. Specific firm-level manifestations point to the prevalence of a 'short-term management culture', with focus group members arguing that "operators are constantly in firefighting mode [with] no time to look forward" and "[their] priority is to get the load out". 'Communication difficulties' were highlighted as a further firm-level manifestation of inhibiting culture ('the 'speak' is very geeky, it needs to appeal to a very wide audience in terms of experience"). Further relationship- and network-level manifestations show how this cultural barrier manifests itself in inter-firm relationships and overall network values. Lack of digital exchange standards was prioritised as the second most important barrier to benefit capture. Specific relationshiplevel manifestations point to data-sharing implications (i.e. absence of open exchange), while network-level implications highlight how the lack of standards limits innovation opportunities across the network.

Uncertainty over the business value and business risks was prioritised as the third most important barrier. Its firm-level manifestation 'value uncertainty' highlights its investment implications, which in turn limit the firm's benefit capture opportunities. Its relationship-level manifestation 'uncertainty over value distribution' points to a lack of the openness required for shared benefit capture. Resource limitations were prioritized as the fourth most important barrier. This includes 'limited financial and analytical resources' as firm-level manifestations and overall 'resource imbalance' as an important network-level manifestation that limit the benefit capture opportunities for all firms involved in the network. 
A further range of barriers identified by the focus group (e.g. excessive number of available systems, lack of joined-up offerings among actors, limited integration with road transport customers) were, in the end, not prioritized highly by the group's members.

Position of Table 2: Barriers to benefit capture

Stage Three findings: eliciting recommendations. The third, Delphi-based stage created recommendations for overcoming the benefit capture barriers. They are analyzed and presented here with regard to their firm-level, relationship-level and network-level implications, following Snehota and Hakansson's (1995) business network analysis framework. Detailed recommendations are presented in Appendix 2.

Firm-level recommendations targeted the operators in particular. Attracting younger generations into different organizational roles and providing structured training to illustrate digitalization opportunities were considered critical to overcoming the cultural barriers that limit a firm's benefit capture opportunities. Recommendations also called for targeted research that helps firms to model their digitalization and servitization implications and facilitate their decision-making.

Relationship-level recommendations target the creation of innovative models to understand the risk transfer that underlies servitization efforts. Boosting servitization was identified as a pathway to overcoming the resource barrier. Recommendations targeting the larger network include calls for the establishment of a leadership role to formally coordinate the network, a consortium for standard development, and government involvement. Importantly, a note of caution also emerged arguing that the standards should not be too restrictive, in order not to limit the innovative potential of the individual firms embedded in the network. The findings and their wider implications will be discussed in the next section. 


\section{DISCUSSION \& CONCLUSIONS}

This study set out to advance a business network perspective to conceptualize the implications of digitalization and servitization and examine the barriers affecting capture of the potential benefits. The findings show how a diversity of cultural, technical, strategic and economic barriers limit benefit capture by affecting individual firms, their relationships and their wider networks. By applying a network perspective, the study creates a holistic view on the multi-level nature of the benefit capture challenge posed by digitalization and servitization; it also confirms prior research findings on firm-level barriers (i.e. changeresistant management culture, limitations in financial and analytical resources) (Coreynen et al., 2016) and network-level barriers (i.e. data standards) (DIN, 2016). Adopting a network perspective helps to theorize how the barriers and recommendations contribute to our understanding of network governance mechanisms (resource ties, activity links and actor bonds) in the context of emerging digital networks (Snehota \& Hakansson, 1995).

Resource ties - firms' ability to access each other's resources - are considered critical for benefit creation and capture in business networks. The findings illustrate the importance of access to digital and analytical resources but also highlight a dilemma with regard to the role of resource ties in a digitalization context. Operators represent the source of the network's data resource but at the same time have the least analytical and financial resources to capture the digitalization benefits themselves; their limited interest in creating these data resources threatens the wider network's benefit capture opportunities. The fact that several recommendations specifically target the operator's analytical and financial resources (e.g. skills development and investment support) indicates that the operator's critical role has been identified and that targeted support is required to benefit the wider network.

The role of activity links (operational connections and mutual adaptations) is illustrated by the findings showing how communication difficulties and lack of data standards threaten 
benefit capture on the relational and network level. Corresponding recommendations (i.e. standards development, consortium formation) directly targeting operational connections and mutual adaptations facilitate benefit capture in emerging digital networks.

The findings also illustrate the importance of actor bonds (members' relationships and mutual perceptions) by showing how the network members' entrenched perceptions curb the business model changes required to realize the benefit capture opportunities offered by digitalization (i.e. servitization). Several of the recommendations provided (i.e. targeted training to broaden role-understanding and risk-sharing) target actor bond development to stimulate the network's benefit capture opportunities. Despite the particular emerging and digital context of road transport networks, established network governance mechanisms (Snehota \& Hakansson, 1995) seem also to underlie the specific benefit capture barriers and recommendations identified.

\section{Implications for business theory}

The study provides a number of further insights on the implications of digitalization and servitization that go beyond the specifics of the road transport industry. It conceptualizes and illustrates digitalization and servitization as two mutually reinforcing phenomena.

Digitalization creates advanced product-use insights which enable manufacturers to manage the risks of providing their products as a service:

"The technology change brought about a new realisation ... it was no longer enough for us to say this is the product, this is the component, this is the features and the benefit, we had to start improving the performance. [..] we then had to start total cost of ownership or total cost of operation [considerations] ... and develop new business models around that."

(Chief Executive Officer - Vehicle manufacturer) 
Conversely, servitization implies technology investment and analytical capability provision which stimulates the digitalization of the wider business network:

"The attraction for [telematics provider] is that we provide $100 \%$ of vehicles as services which means more boxes for them and more digital services. [They] don't really care about boxes they would happily use the [competitor] box if they could get the data. The data is the value here as we know... it's a land grab because there are some competitors coming around, so it's really about signing up fleets... as quick[ly] as they can."

(Director - Vehicle manufacturer)

The link between digitalization (a technology innovation) and servitization (a business model innovation) represents an important angle for IS-based digitalization research and theory development (Fichman et al., 2014; Yoo et al., 2012).

The study also illustrates how the conceptualization of the digitalization phenomenon is advanced through a business network perspective. This perspective conceptualizes digitalization as a multi-level phenomenon, integrating prior firm-level (Nambisan, 2013; Yoo et al., 2012) or network-level (Venkatraman, El Sawy, Pavlou, \& Bharadwaj, 2014) conceptualizations, and highlights how the benefit capture opportunities are shaped by crosslevel factors (e.g. shared data resources) and multi-level factors (e.g. culture).

This paper specifically identifies the emergent business network as a distinct digitalization research context future IS should explore. While prior network-level studies have made assumptions about the existence of focal firms or products that galvanize the distributed developments (Nambisan, 2013; Yoo et al., 2012), the present research highlights the benefit capture difficulties in the absence of such a focal point. The lack of data standards or a dominant platform becomes a source of significant uncertainties across the emergent network, the individual firms and their relationships. As emergent networks are likely to 
become a more common form of collaboration in a digitalization context (Lyytinen et al., 2016), a business network perspective is shown to be well-suited to examine its varied management challenges.

The study's focus on benefit capture barriers and their specific manifestations in particular contributes to the development of a 'network-based capability perspective on digitalization' (as proposed by Venktraman et al 2014). Indeed, the skill shortages, communication barriers and difficulties in standards creation identified illustrate Venkatraman et al.’s proposed operational capabilities required to convert digitalization potential into tangible benefits. Persistent management culture, antagonistic relationships, resistance to change and the discounting of changing roles point to the dynamic capabilities that networks require in order to perform the adaptations needed for capturing the benefits of digitalization. The difficulty of recognizing digitalization's benefit potential and equitably sharing it illustrates Venktraman et al.'s proposed improvisational capabilities, which allow networks to recognize the intrinsic value of these innovations and reconfigure their capabilities accordingly.

Findings from the present research provide important illustrations of network capabilities for digitalization but also extend the proposed network-level conceptualization (Venkatraman et al., 2014). Following the arguments of a business network perspective (Johanson \& Vahlne, 2011), a capability view should differentiate between firm- and relationship-level and network-level capabilities in order to explicitly consider the critical role that individual firms and their relationships play in creating network-level implications.

\section{Implications for business practice}

The study has also pinpointed a number of management implications (in addition to the specific recommendations that the Delphi-based inquiry produced). It shows how critically important it is for management to extend its scope beyond the firm if the benefit potential of 
digitalization is to be captured. Digitalization requires managers to carefully balance their firm's interests with the network's interests to strengthen the wider business network's health. Arguably, balancing these interests for emergent business networks is particularly challenging but also critical as collaborations are ad hoc and network boundaries are fluid (Inkpen \& Tsang, 2005; Lyytinen et al., 2016).

Managers can draw important lessons from the road transport case, which highlights how the core data source is created by operators but used by manufacturers and telematics providers to capture the benefits of digitalization. Creating opportunities for the product user to capture immediate and tangible benefits from digitalization and the corresponding service provision is critical. Specific initiatives to help product users to overcome the analytical challenge (i.e. training and development with regard to decision-making tools) and to clarify the extent of obtainable benefits (i.e. independent research) are outlined.

\section{Opportunities for future research}

The study creates a number of specific opportunities for IS research and theory-building. In particular, it has established a manufacturer's servitization effort as one of the main beneficiaries from digitalization; this raises important questions about the alignment of digitalization and servitization efforts. IS research on business/IT alignment has established a strong theoretical basis for investigating governance configurations and processes (see Luftman \& Kempaiah, 2007). IS research is best-placed to investigate the 'digitalization alignment challenge' where the alignment of service, marketing, product development and IT is required to establish integrated digitalization strategies.

This paper also highlights the importance of distributing digitalization benefits equitably to facilitate sharing of digital resources. Current IT value models, however, do not cater well for understanding the value of shared digital resources or their distribution in a network context (see Cao, Duan, Cadden, \& Minocha, 2016; Grover \& Kohli, 2012). Developing the 
theoretical understanding and practical tools for equitable benefit distribution would be an important focus for future research.

In addition, this study highlights the importance of focusing on traditional industries to understand digitalization. Arguably, for traditional industries, digitalization represents a bigger challenge than for industries which are consistently at the forefront of digital innovation and exploitation. So far, digitalization research has concentrated on high-tech environments (Lyytinen et al., 2016) but opportunities are created for IS research to expand into business environments that traditionally are neither the focus nor the beneficiary of IS research and theorization.

For the present study, a business network perspective together with a qualitative approach was adopted to investigate the implications of digitalization. However, future research should expand the conceptualization of digitalization as a network phenomenon and apply social network analysis tools (Scott, 2012) in order to explore the impact of relationship strengths and to be able to quantify the benefit capture opportunities. A business network perspective on digitalization provides substantial future research opportunities that will require diverse theoretical and methodological perspectives.

\section{Limitations of this study}

Despite the range of its contributions, it is important to note the study's limitations. Firstly, by integrating different methods, the study also integrates their inherent limitations. The focus group method, for example, is sensitive to participants' interactions, and perspectives provided early in the group process can overshadow the further elicitation process (Sutton \& Arnold, 2013). Although the study used cards as permanent records to ensure individual contributions were retained, the impact that social dynamics had on the findings cannot be excluded. The Delphi method carries the risk of creating specific topicrelated information instead of consolidated generalizable insights (Hsu \& Sandford, 2007). 
The present study has sought to outline the specific insights created (Appendix 2) but also to provide a higher-level interpretation to increase the findings' applicability. Although a variety of recommendations were elicited, greater panel diversity might have generated further recommendations.

Secondly, as the research participants possess a high level of telematics experience and have had substantial exposure to service-based business models, they may not be representative of the wider UK road transport industry. The industry spans an even greater range of levels of skill and experience, which limits the findings' immediate transferability to the whole industry.

Thirdly, the study's focus, the road transport industry, is singled out in the literature on account of its hesitancy with respect to IT innovation (Sternberg, Prockl, \& Holmström, 2014). As adoption and utilization depend on previous exposure (Jeyaraj, Rottman, \& Lacity, 2006), the findings should be verified in other industries before adopting the study's recommendations.

Notwithstanding these limitations, this study provides important insights into the wider implications of digitalization and the corresponding servitization business model. Although common definitions describe digitalization as the transformation of 'everyday objects and products' (Whitmore et al., 2015), the research summarized here suggests that the impact of digitalization actually extends beyond objects and products. Digitalization also involves the transformation both of business models and of management approaches, with complex implications for wider business networks. 


\section{REFERENCES}

Baines, T., \& Lightfoot, H. 2013. Made to serve: How manufacturers can compete through servitization and product service systems. Chichester, UK: John Wiley \& Sons.

Baines, T., Lightfoot, H. W., Benedettini, O., \& Kay, J. M. 2009. The servitization of manufacturing: a review of literature and reflection on future challenges. Journal of Manufacturing Technology Management, 20(5): 547-567.

Barrett, M., Davidson, E., Prabhu, J., \& Vargo, S. L. 2015. Service innovation in the digital age: Key contributions and future directions. MIS Quarterly, 39(1): 135-154.

Benedettini, O., Neely, A., \& Swink, M. 2015. Why do servitized firms fail? A risk-based explanation. International Journal of Operations \& Production Management, 35(6): 946-979.

Bharadwaj, A., El Sawy, O. A., Pavlou, P. A., \& Venkatraman, N. 2013. Digital business strategy: toward a next generation of insights. MIS Quarterly, 37(2): 471-482.

Braun, V., \& Clarke, V. 2006. Using thematic analysis in psychology. Qualitative Research in Psychology, 3(2): 77-101.

Cao, G., Duan, Y., Cadden, T., \& Minocha, S. 2016. Systemic capabilities: The source of IT business value. Information Technology \& People, 29(3): 556-579.

Cole, L. 2016. Keeping track, Motor Transport: 28-29.

Coreynen, W., Matthyssens, P., \& Van Bockhaven, W. 2016. Boosting servitization through digitization: Pathways and dynamic resource configurations for manufacturers.

Industrial Marketing Management, $\mathrm{xx}(\mathrm{xx})$ : $\mathrm{xx}-\mathrm{xx}$.

D'Aunno, T. A., \& Zuckerman, H. S. 1987. A life-cycle model of organizational federations: The case of hospitals. Academy of Management Review, 12(3): 534-545.

Dalsace, F., Ulaga, W., \& Renault, C. 2012. Fleet solutions: From selling tires to selling kilometers: HEC Paris.

DIN. 2016. German standardization roadmap on industry 4.0. Berlin, Germany: DIN/Deutsche Kommission Elektrotechnik.

Donohoe, H. M., \& Needham, R. D. 2009. Moving best practice forward: Delphi characteristics, advantages, potential problems, and solutions. International Journal of Tourism Research, 11(5): 415-437.

Elg, U. 2000. Firms' home-market relationships: their role when selecting international alliance partners. Journal of International Business Studies, 31(1): 169-177. 
Fichman, R. G., Dos Santos, B. L., \& Zheng, Z. E. 2014. Digital innovation as a fundamental and powerful concept in the Information Systems curriculum. MIS Quarterly, 38(2): 329-353.

Fisk, R. P., Patricio, L., Kowalkowski, C., Kindström, D., \& Witell, L. 2011. Internalisation or externalisation? Examining organisational arrangements for industrial services. Managing Service Quality: An International Journal, 21(4): 373-391.

Ford, D., Gadde, L., Hakansson, H., \& Snehota, I. 2003. Managing business networks. Chichester, UK: John Wiley.

Gadde, L.-E. 2014. Strategizing at the boundaries of firms. IMP Journal, 8(2): 51-63.

Grover, V., \& Kohli, R. 2012. Cocreating IT value: New capabilities and metrics for multifirm environments. MIS Quarterly, 36(1): 225-232.

Grubic, T. 2014. Servitization and remote monitoring technology: A literature review and research agenda. Journal of Manufacturing Technology Management, 25(1): 100-124.

Halinen, A., \& Törnroos, J.- $\AA$. 2005. Using case methods in the study of contemporary business networks. Journal of Business Research, 58(9): 1285-1297.

Henneberg, S., Mouzas, S., \& Naudé, P. 2006. Network pictures: Concepts and representations. European Journal of Marketing, 40(3/4): 408-429.

Henneberg, S., Naudé, P., \& Mouzas, S. 2010. Sense-making and management in business networks - Some observations, considerations, and a research agenda. Industrial Marketing Management, 39(3): 355-360.

Hirschhorn, L., \& Gilmore, T. 1992. The new boundaries of the "boundaryless" company. Harvard business review, 70(3): 104-115.

Hsu, C.-C., \& Sandford, B. A. 2007. The Delphi technique: Making sense of consensus. Practical Assessment, Research \& Evaluation, 12(10): 1-8.

Iansiti, M., \& Levien, R. 2004. Strategy as ecology. Harvard business review, 82(3): 68-81.

Inkpen, A. C., \& Tsang, E. W. 2005. Social capital, networks, and knowledge transfer. Academy of Management Review, 30(1): 146-165.

Järvensivu, T., \& Törnroos, J.- $\AA$. 2010. Case study research with moderate constructionism: Conceptualization and practical illustration. Industrial Marketing Management, 39(1): 100-108. 
Jeyaraj, A., Rottman, J. W., \& Lacity, M. C. 2006. A review of the predictors, linkages, and biases in IT innovation adoption research. Journal of Information Technology, 21(1): 123.

Johanson, J., \& Vahlne, J.-E. 2011. Markets as networks: implications for strategy-making. Journal of the Academy of Marketing Science, 39(4): 484-491.

Kastalli, I. V., \& Van Looy, B. 2013. Servitization: Disentangling the impact of service business model innovation on manufacturing firm performance. Journal of Operations Management, 31(4): 169-180.

Kindström, D., \& Kowalkowski, C. 2014. Service innovation in product-centric firms: A multidimensional business model perspective. Journal of Business \& Industrial Marketing, 29(2): 96-111.

Kowalkowski, C. 2010. What does a service-dominant logic really mean for manufacturing firms? Journal of Manufacturing Science and Technology, 3(4): 285-292.

Kreps, D., \& Kimppa, K. 2015. Theorising Web 3.0: ICTs in a changing society. Information Technology \& People, 28(4): 726-741.

Li, Y.-R. 2009. The technological roadmap of Cisco's business ecosystem. Technovation, 29(5): 379-386.

Luftman, J., \& Kempaiah, R. 2007. An Update on business-IT alignment: 'A line' has been drawn. MIS Quarterly Executive, 6(3): 165-177.

Lusch, R. F., \& Nambisan, S. 2015. Service innovation: A service-dominant logic perspective. MIS Quarterly, 39(1): 155-175.

Lyytinen, K., Yoo, Y., \& Boland Jr, R. J. 2016. Digital product innovation within four classes of innovation networks. Information Systems Journal, 26(1): 47-75.

Matthyssens, P., Vandenbempt, K., \& Weyns, S. 2009. Transitioning and co-evolving to upgrade value offerings: A competence-based marketing view. Industrial Marketing Management, 38(5): 504-512.

McKinsey Global Institute. 2015. The internet of things: Mapping the value beyond the hype, Vol. 2016: Cisco.

Miles, M. B., \& Huberman, M. A. 1994. Qualitative data analysis: an expanded sourcebook. Thousand Oaks, California: SAGE Publications, Inc.

Möller, K. 2013. Theory map of business marketing: Relationships and networks perspectives. Industrial Marketing Management, 42(3): 324-335. 
Möller, K., \& Halinen, A. 1999. Business relationships and networks: Managerial challenge of network era. Industrial Marketing Management, 28(5): 413-427.

Möller, K., \& Rajala, A. 2007. Rise of strategic nets-New modes of value creation. Industrial Marketing Management, 36(7): 895-908.

Möller, K., \& Svahn, S. 2003. Managing strategic nets a capability perspective. Marketing Theory, 3(2): 209-234.

Möller, K., \& Svahn, S. 2009. How to influence the birth of new business fields-Network perspective. Industrial Marketing Management, 38(4): 450-458.

Munksgaard, K. B., \& Medlin, C. J. 2014. Self-and collective-interests: Using formal network activities for developing firms' business. Industrial Marketing Management, 43(4): 613-621.

Musson, E., Bigdeli, A., \& Baines, T. 2015. Delivering growth: Exploring the potential of advanced services within the road transport industry: Aston University, Birmingham, UK.

Nadj, M., Jegadeesan, H., Maedche, A., Hoffmann, D., \& Erdmann, P. 2016. A situation awareness driven design for predictive maintenance systems European Conference of Information Systems.

Nambisan, S. 2013. Information Technology and Product/Service Innovation: A Brief Assessment and Some Suggestions for Future Research. Journal of the Association for Information Systems, 14(4): 215-226.

Neely, A. 2008. Exploring the financial consequences of the servitization of manufacturing. Operations Management Research, 1(2): 103-118.

Ng, I., Parry, G., Smith, L., Maull, R., \& Briscoe, G. 2012. Transitioning from a goodsdominant to a service-dominant logic: Visualising the value proposition of Rolls-Royce. Journal of Service Management, 23(3): 416-439.

Opresnik, D., \& Taisch, M. 2015. The value of Big Data in servitization. International Journal of Production Economics, 165: 174-184.

Pfeffer, J., \& Salancik, G. R. 1978. The external control of organizations: A resource dependence approach: Stanford University Press.

Provan, K. G., Fish, A., \& Sydow, J. 2007. Interorganizational networks at the network level: A review of the empirical literature on whole networks. Journal of Management, 33(3): 479-516. 
Raab, J., \& Kenis, P. 2009. Heading Toward a Society of Networks Empirical Developments and Theoretical Challenges. Journal of Management Inquiry, 18(3): 198-210.

Raddats, C., Baines, T., Burton, J., Story, V. M., \& Zolkiewski, J. 2016. Motivations for servitization: the impact of product complexity. International Journal of Operations \& Production Management, 36(5): 572-591.

Ramos, C., Roseira, C., Brito, C., Henneberg, S., \& Naudé, P. 2013. Business service networks and their process of emergence: The case of the Health Cluster Portugal. Industrial Marketing Management, 42(6): 950-968.

Riggins, F. J., \& Wamba, S. F. 2015. Research directions on the adoption, usage, and impact of the internet of things through the use of big data analytics. Paper presented at the System Sciences (HICSS), 2015 48th Hawaii International Conference on.

Schroeder, A., \& Kotlarsky, J. 2015. Digital resources and their role in advanced service provision: a VRIN analysis. month.

Scott, J. 2012. Social network analysis. London, UK: Sage.

Snehota, I., \& Hakansson, H. 1995. Developing relationships in business networks: Routledge London.

Sternberg, H., Prockl, G., \& Holmström, J. 2014. The efficiency potential of ICT in haulier operations. Computers in Industry, 65(8): 1161-1168.

Story, V. M., Raddats, C., Burton, J., Zolkiewski, J., \& Baines, T. in press. Capabilities for advanced services: A multi-actor perspective. Industrial Marketing Management, $\mathrm{xx}(\mathrm{xx})$ : $\mathrm{xx}-\mathrm{xx}$.

Sutton, S. G., \& Arnold, V. 2013. Focus group methods: Using interactive and nominal groups to explore emerging technology-driven phenomena in accounting and information systems. International Journal of Accounting Information Systems, 14(2): 81-88.

Tikkanen, H. 1998. The network approach in analyzing international marketing and purchasing operations: a case study of a European SME's focal net 1992-95. Journal of Business \& Industrial Marketing, 13(2): 109-131.

Tilson, D., Lyytinen, K., \& Sørensen, C. 2010. Digital infrastructures: The missing IS research agenda. Information Systems Research, 21(5): 748-759.

Valtakoski, A. in press. Explaining servitization failure and deservitization: A knowledgebased perspective. Industrial Marketing Management, xx(xx): xx-xx.

Van Den Belt, H. 2003. How to engage with experimental practices? Moderate versus radical constructivism. Journal for General Philosophy of Science, 34(2): 201-219. 
Vargo, S. L., \& Lusch, R. F. 2008. Service-dominant logic: continuing the evolution. Journal of the Academy of Marketing Science, 36(1): 1-10.

Vargo, S. L., \& Lusch, R. F. 2010. From repeat patronage to value co-creation in service ecosystems: a transcending conceptualization of relationship. Journal of Business Market Management, 4(4): 169-179.

Vendrell-Herrero, F., Bustinza, O. F., Parry, G., \& Georgantzis, N. 2017. Servitization, digitization and supply chain interdependency. Industrial Marketing Management, 60: 69-81.

Venkatraman, N. V., El Sawy, O. A., Pavlou, P. A., \& Bharadwaj, A. 2014. Theorizing digital business innovation: platforms and capabilities in ecosystems, Fox School of Business Research Paper.

Walter, A., Auer, M., \& Ritter, T. 2006. The impact of network capabilities and entrepreneurial orientation on university spin-off performance. Journal of business venturing, 21(4): 541-567.

Wang, K. 2016. Intelligent predictive maintenance (IPdM) System-Industry 4.0 Scenario. WIT Transactions on Engineering Sciences, 113: 259-268.

Watson, R. T., Boudreau, M.-C., Li, S., \& Levis, J. 2010. Telematics at UPS: En route to energy informatics. MIS Quarterly Executive, 9(1): 1-11.

Welch, C., \& Wilkinson, I. 2002. Idea logics and network theory in business marketing. Journal of Business-to-Business Marketing, 9(3): 27-48.

Whitmore, A., Agarwal, A., \& Da Xu, L. 2015. The internet of things: A survey of topics and trends. Information Systems Frontiers, 17(2): 261-274.

Yoo, Y., Boland Jr, R. J., Lyytinen, K., \& Majchrzak, A. 2012. Organizing for innovation in the digitized world. Organization Science, 23(5): 1398-1408.

Yoo, Y., Henfridsson, O., \& Lyytinen, K. 2010a. Research commentary-The new organizing logic of digital innovation: An agenda for information systems research. Information Systems Research, 21(4): 724-735.

Yoo, Y., Lyytinen, K. J., Boland, R. J., \& Berente, N. 2010b. The next wave of digital innovation: Opportunities and challenges: A report on the research workshop'Digital Challenges in Innovation Research'. Available at SSRN 1622170.

Zaefarian, G., Henneberg, S., \& Naudé, P. 2011. Resource acquisition strategies in business relationships. Industrial Marketing Management, 40: 862-874.

Zittrain, J. L. 2006. The generative internet. Harvard Law Review, 119(7): 1974-2040. 
TABLE 1

Benefit capture opportunities and interdependency

\begin{tabular}{|c|c|}
\hline \multicolumn{2}{|l|}{ Transport Operator } \\
\hline Benefit Potential & External Dependency \\
\hline $\begin{array}{l}\text { Driver behaviour data permits targeted driver } \\
\text { management: } \\
\text { - improved fuel efficiency \& tyre life } \\
\text { - fewer accidents } \\
\text { - reduced maintenance costs (e.g. brakes) } \\
\text { - accurate damage reporting } \\
\text { - reduced insurance premiums } \\
\text { Vehicle health data permits improved fleet } \\
\text { management: } \\
\text { - cost transparency } \\
\text { - maintenance optimization } \\
\text { - protection of operator license } \\
\text { - increased fleet reliability } \\
\end{array}$ & $\begin{array}{l}\text { OEMs (directly or via telematics } \\
\text { provider) control: } \\
\text { - extent of raw data \& analytical } \\
\text { results made available } \\
\text { - data format \& measurement } \\
\text { parameters used } \\
\text { - data robustness }\end{array}$ \\
\hline \multicolumn{2}{|l|}{ OEM (truck or component) } \\
\hline Benefit Potential & External Dependency \\
\hline $\begin{array}{l}\text { Vehicle health data permits: } \\
\text { - service operation optimization (e.g. } \\
\text { technician grading) } \\
\text { - insights into component reliability } \\
\text { - R\&D feedback } \\
\text { Driver behaviour data permits: } \\
\text { - verification of warranty claims } \\
\text { - customer advisory role } \\
\text { Service business model enablement via driver } \\
\text { \& vehicle data permits: } \\
\text { - customer profiling (e.g. risk estimation) } \\
\text { - refined service contract pricing } \\
\text { - service compliance monitoring (e.g. uptime) }\end{array}$ & $\begin{array}{l}\text { Operator controls data access through: } \\
\text { - implementation/activation }{ }^{3} \text { of } \\
\text { specific telematics system } \\
\text { - adoption of service contract (which } \\
\text { implies full data access) }\end{array}$ \\
\hline \multicolumn{2}{|l|}{ Telematics Technology \& Service Provider } \\
\hline Benefit Potential & External Dependency \\
\hline $\begin{array}{l}\text { Data collection and processing represents the } \\
\text { core business. Access to additional data sources } \\
\text { permits: } \\
\text { - refinement of analytical processes } \\
\text { - additional service propositions (e.g. } \\
\text { optimized routeing) } \\
\text { - understanding of customer operations } \\
\text { - development into market standard }\end{array}$ & $\begin{array}{l}\text { Data access is controlled through: } \\
\text { - telematics system adoption (by } \\
\text { operators or manufacturers) } \\
\text { - obtaining access to core vehicle data } \\
\text { (from manufacturers) } \\
\text { - creation of standard platforms for } \\
\text { additional assets (e.g. trailers, } \\
\text { refrigeration units) }\end{array}$ \\
\hline
\end{tabular}

${ }^{3}$ Operators may choose either not to install telematics or to disable them. 
TABLE 2

Barriers to benefit capture

'Inhibiting culture' as a barrier

Firm-level manifestations:

- Short-term management culture: Capturing the benefit potential requires strategic development of analytical and innovation capabilities, which conflicts with the operational primacy prevalent among operators.

- Resistance to change: Converting advanced insights into behavioural change and tangible benefits requires changes in management practice (e.g. introduction of driver incentive systems). Operators' ageing workforces are seen as an obstruction to such changes and to the development of a digital vision.

Relationship-level manifestations:

- Communication difficulties: Digital skills vary significantly among actors, impeding exploration of opportunities for joint innovation and integration.

- Enduring perceptions: Persistence of traditional views among actors (despite changes in business models and capabilities) limits benefit capture. Manufacturers are still recognized for their product but not for their digital expertise and service capabilities.

Network-level manifestation:

- Antagonistic transactional culture: Collaborative partnerships between actors are critical for the joint exploitation of digital opportunities. An excessive focus on price and negotiations has limited the formation of partnerships in road transport.

'Lack of digital exchange standards' as a barrier*

Relationship-level manifestation:

- Absence of open exchange practices: The practice of fractional exchange of available data limits the extent of the benefits that can be created. Due to IP considerations, truck manufacturers, in particular, only share a fraction of the data created.

Network-level manifestation:

- Lack of agreed data format and measurement standards: Diverse data formats and standards for measuring core attributes (e.g. harsh cornering) mean that digital integration and transformation require extensive effort, limiting interpretation and innovation opportunities across the network.

'Value and risk uncertainty' as a barrier*

Firm-level manifestation:

- Value uncertainty: Operational diversity among actors makes it very difficult to estimate the potential value or risk of full engagement with digitalization. The absence of a clear understanding of return-oninvestment (ROI) limits investment in infrastructure and capabilities, although this is required if the full benefits of digitalization are to be captured.

Relationship-level manifestation:

- Uncertainty over value distribution: Lack of transparency regarding benefit distribution limits openness, even though openness is essential to shared digital innovation. Operators, in particular, call for assurance over the equitable distribution of value from shared digital resources.

'Resource limitations' as a barrier*

Firm-level manifestation:

- Limited financial and analytical resources: Widespread lack of analytical skills and lack of investment limit the ability to capture the wider benefit potential of digitalization. Particularly among operators, investment demands from other business areas are regularly prioritized as more critical ("other demands on same money pot of the business").

Network-level manifestation:

- Resource imbalance: A substantial imbalance between levels of digital and analytical expertise and a diversity of operational practices create needs across the network that are too extensive to be supported efficiently.

*Not all barriers create immediate implications across all three levels of analysis. 
APPENDIX 1

Participants in the research

\begin{tabular}{|l|l|l|l|l|l|}
\hline \multicolumn{2}{|l|}{ Job Title of Participant } & Type of Firm & $\begin{array}{l}\text { Stage } \\
1\end{array}$ & $\begin{array}{l}\text { Stage } \\
2\end{array}$ & $\begin{array}{l}\text { Stage } \\
3\end{array}$ \\
\hline 1 & Managing Director & Telematics provider & X & X & \\
\hline 2 & Vice President & Telematics provider & X & X & \\
\hline 3 & Account Manager & Telematics provider & & X & X \\
\hline 4 & Channel Director & Telematics provider & & X & \\
\hline 5 & Business Development Manager & Fleet management services & & X & \\
\hline 6 & Business Development Executive & Fleet management services & & X & \\
\hline 7 & Fleet Manager & Transport operator A & & X & \\
\hline 8 & Fleet Manager & Transport operator B & & X & \\
\hline 9 & Director - Technical Services & Transport operator C & & X & X \\
\hline 10 & Owner-Manager & Transport operator D & X & & \\
\hline 11 & Director & Transport operator E & X & X & X \\
\hline 12 & Director - Aftersales & Vehicle manufacturer & & X & \\
\hline 13 & Director - Telematics Services & Vehicle manufacturer & & $\mathrm{X}$ & \\
\hline 14 & Chief Executive Officer (retired) & Vehicle manufacturer & $\mathrm{X}$ & $\mathrm{X}$ & $\mathrm{X}$ \\
\hline 15 & Retail Director & Vehicle manufacturer & & & $\mathrm{X}$ \\
\hline 16 & Dealer Principal & Vehicle manufacturer & $\mathrm{X}$ & & $\mathrm{X}$ \\
\hline 17 & Director - Service Management & Vehicle manufacturer & & & $\mathrm{X}$ \\
\hline 18 & Chief Innovation Officer & Component manufacturer & & $\mathrm{X}$ & \\
\hline 19 & Commercial Director & Component manufacturer & & $\mathrm{X}$ & \\
\hline 20 & Innovation Manager & Component manufacturer & & $\mathrm{X}$ & \\
\hline 21 & Services Innovation Manager & Component manufacturer & $\mathrm{X}$ & $\mathrm{X}$ & \\
\hline
\end{tabular}

APPENDIX 2

Detailed recommendations for overcoming the benefit capture barriers

Addressing the 'cultural' barrier

\section{The panel arrived at the following four recommendations:}

- Attract younger generations into the industry. The cultural change needed to capture fully the opportunities to benefit from digitalization requires staff open to the potential of connected technologies and data-driven decision-making. For the road transport industry, integrating a new generation of staff and their thinking across the different roles within organizations (e.g. driver, technician, manager) is essential to creating the necessary openness and innovation potential.

- Integrate telematics training across different roles. The ability to capture the benefits of digitalization requires a diverse, constantly evolving range of technical and analytical skills. The panel members emphasized the importance not only of formally integrating digital skills into common driver-training modules but also of offering specific courses across the industry to enhance the innovation potential for individual organizations, for their relationships and for the entire network.

- Innovative management practices. To capture all of the benefits, management practices and policies need to evolve alongside digitalization. The panel members emphasized the need to understand the management implications and to develop critical guidance on the new management practices that are required (e.g. driver incentive systems) in order to realize digitalization's potential.

- Allocating the leadership role. The growth of interdependencies among organizations and the lack of a focal, coordinating leader limit the entire network's innovation potential. The panel members underlined the importance of industry associations stepping up to the leadership challenge in order to help coordinate the process of digital integration. 


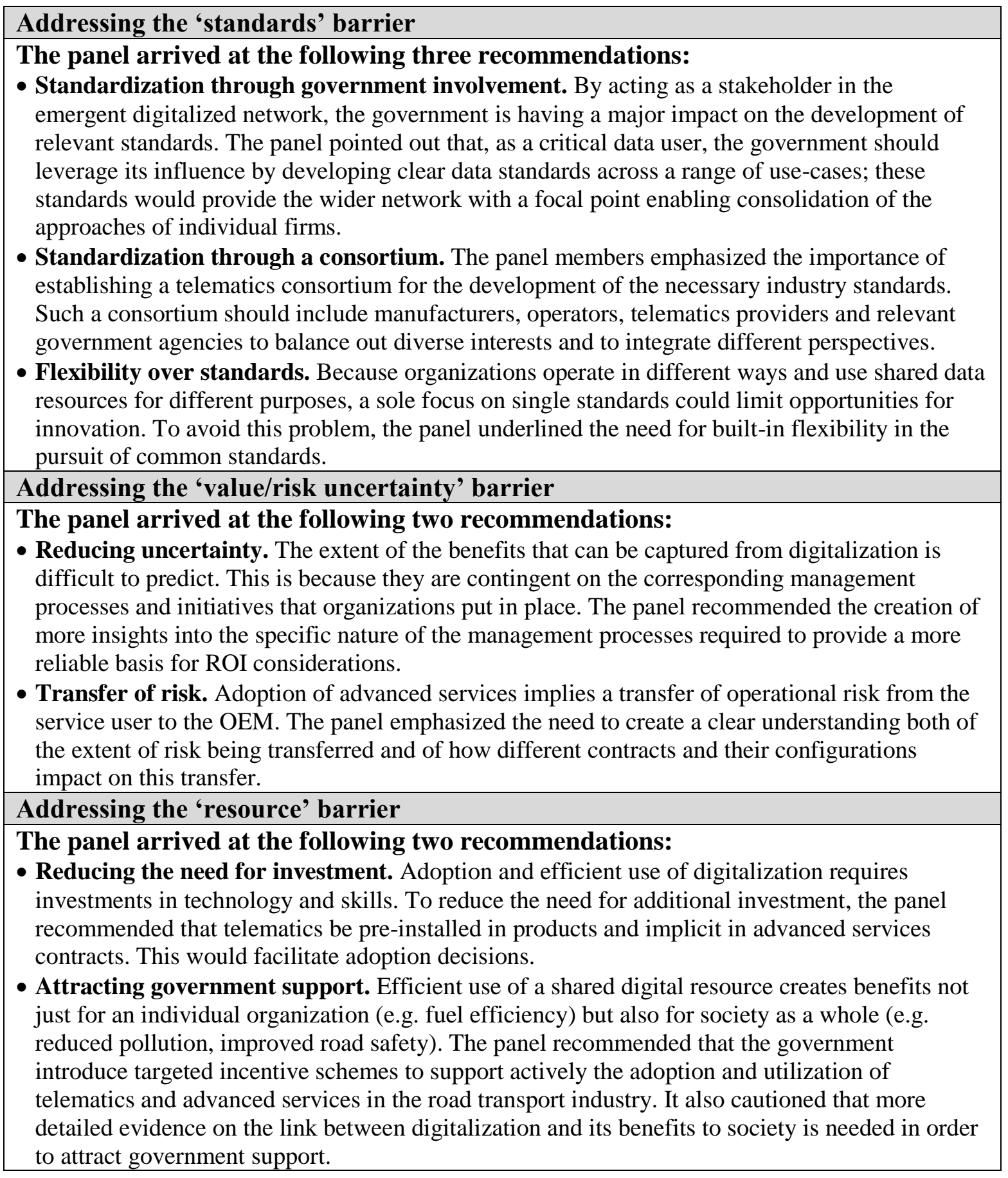

